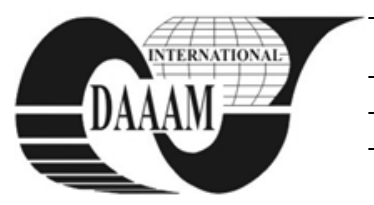

Annals of DAAAM for 2012 \& Proceedings of the 23rd International DAAAM Symposium, Volume 23, No.1, ISSN 2304-1382 ISBN 978-3-901509-91-9, CDROM version, Ed. B. Katalinic, Published by DAAAM International, Vienna, Austria, EU, 2012 Make Harmony between Technology and Nature, and Your Mind will Fly Free as a Bird

\title{
MODELING, SIMULATION AND CONTROL OF THE SLAUGHTER COMPLEX
}

\author{
SIRB, V[ali] - C[hivuta] \& EGRI, A[ngela]
}

\begin{abstract}
This paper shows how simulation modeling and control of a support section with Petri Nets using Visual Object Net ++ . During development of this software, special attention was given to use intuitive, thanks to ease of design, simulation fast and clear documentation of Petri networks. In the current version, events / terms of Petri networks planned with infinite capacity are allowed.

Key words: Petri network, support section, slaughter complex management, mechanized complex
\end{abstract}

\section{INTRODUCTION}

Key innovation of Visual Object Net ++ is support for new network elements further, in addition to traditional discrete Petri networks: continuous transitions and positions. Continuous updates to transitions is that they behave in a continuous execution, execution speed can be attributed to the transition described by differential equations with continuous processes which shape the behavior of continuous dynamic becomes accessible. Once further evidence can be combined with the discrete concept allows modeling complex hybrid dynamical systems. Including elements of continuous Petri Nets in Petri traditional networks, until now reserved for describing discrete event systems, bringing the two concepts so far separated. A special feature ( Egri, A, ; Sirb, V. ; 2010) of the program is continuous and discrete chips displacement animation. Thus it is easier to follow the model and the dynamic behavior of network. Before beginning the simulation should take place in simulation mode by clicking the Start button. After that, the network will be checked and formulas will be compiled and in some cases if necessary, will receive some error messages.

\section{STRUCTURE AND FUNCTION OF THE SUPPORT SECTION SIMULATION}

Support sections are arranged on the entire length of slaughter and moving to the front on the extent of coal extraction, a well established sequence (fig.1). A support section (fig.2) consists of the following main elements: the element or shield barriers 1, 2 soles, now foot-shield elements 3, 4 beams, beam-joint shield 5, hydraulic support pillars 6, extensible beams (folding and / or sliding ) 7 , hydraulic cylinder for operating the extensible beam 8 and 9 hydraulic pusher. Operations that the support sections perform are the same for all: relief (download) columns hydraulic displacement section, strain and displacement hydraulic pillars to the front of the carrier with scraper. The section beam is intended to cover the surface created by extracting coal roof and took over direct pressure is the main element of protection from falls or falling rocks. Sole section is to send the hearth hewing rocks, roof pressure and weight machines (Sirb, V. ; 2008). The shield is to protect the slaughter space from therock fall in the collapse zone. When hydraulic pillars have their higher supports on the shield, it has a bearing function.To avoid penetration of sterile material in the roof layer and the collapse zone in the work space of the slaughter, shields are provided with extensible side hydraulic or spring.

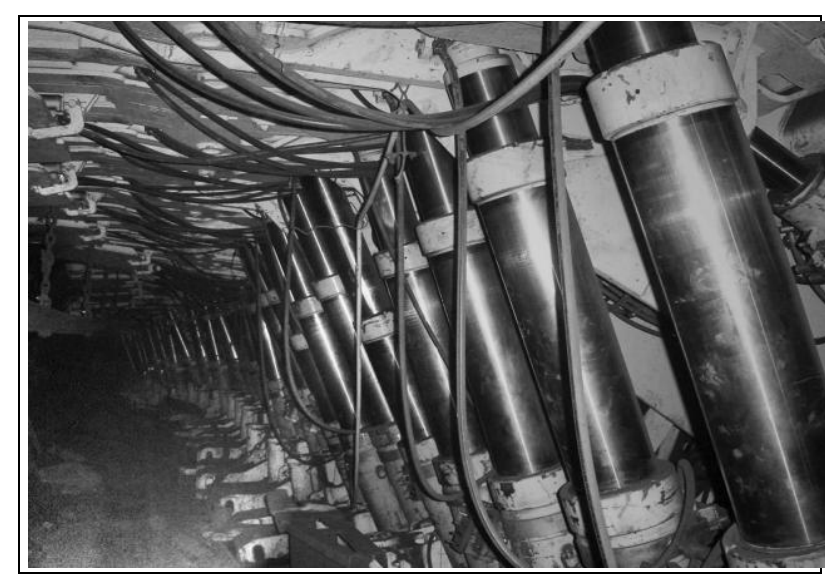

Fig. 1. Support section

When driving an automatic support section, needs to know at any time its position towards or against a neighboring sections of slaughter axis and position of each point of the department depending on the direction of advancement slaughter tilt and relative position between ceiling and fireplace slaughter.

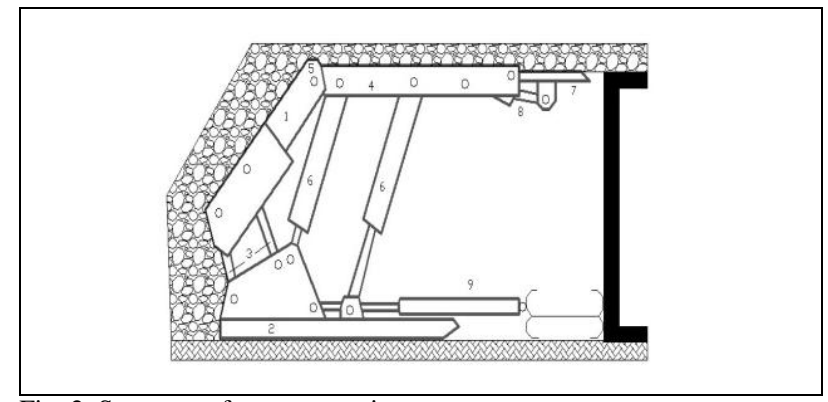

Fig. 2. Structure of support section

For modeling the support section we consider the scheme of such section placed in a cartesian axis system (fig.3). We know, of construction, size of $\mathrm{AB}, \mathrm{AA}$ ', $\mathrm{A}^{\prime} \mathrm{B}$ ', BB ', AS, BC, CD, DE, BE, EF, FD, EJ, RJ, JJ', FK, KK ', FG, GQ, FL, LL ', FP, MM', NN ', NM, NH, MH, HR', HR, HI, RI and AS. It is thought that pillar sizes varying 
lengths $\mathrm{n}$, the cylinder of the main beam M, cylinder and cylinder beam I beam folding sliding $\mathrm{J}$.

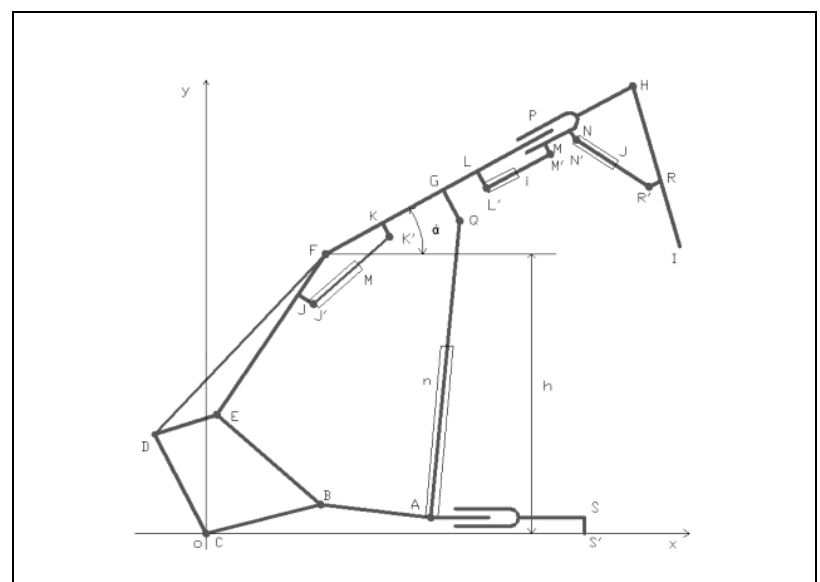

Fig. 3. Support section model

\section{MODELING, SIMULATION AND CONTROL RESULTS}

Simulation of the support section was performed starting from modeling them using Petri networks (fig.4) using the Visual Object Net. The simulated work was done in the window, the simulation started after activating the Start button in the toolbar's main menu and execution simulation environment Run Code of simulation window. Control of the support section begins with storing tokens in a position $\mathrm{P} 1$, then combine cutting command gets the first strip to determine and indicate the production of the first event. After execution first transitions token reaches the position P2 which indicate evniment next production, positioning the visor. This algorithm is applied to each of the positions P1-P8 producing corresponding events described in the technological process. Transitions are enabled and assigns with a time delay, will indicate the execution of process activities to support the mechanized slaughter. After the last move executed by support section is received the new order of cutting operations by repeating the same algorithm (fig.5).

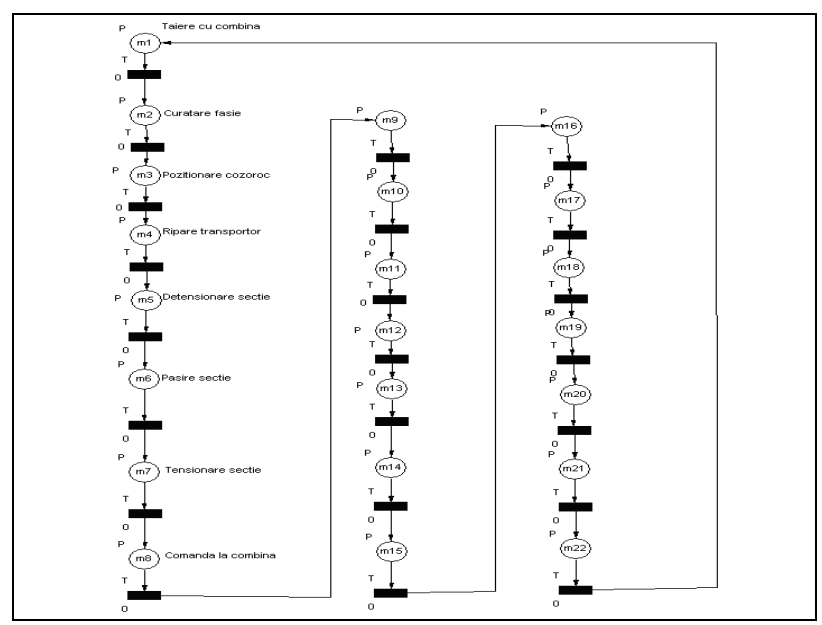

Fig. 4. The Petri Nets model for support section

Slaughter complex management starts with the cutting order of the slaughter combine, indicated by the existence of the token in the second position after the front was prepared, indicated by the existence of the token in the first position. Then the support sections (Patrascoiu, N, ; 2001). a the carrier that discharges the cut material (fig.6).

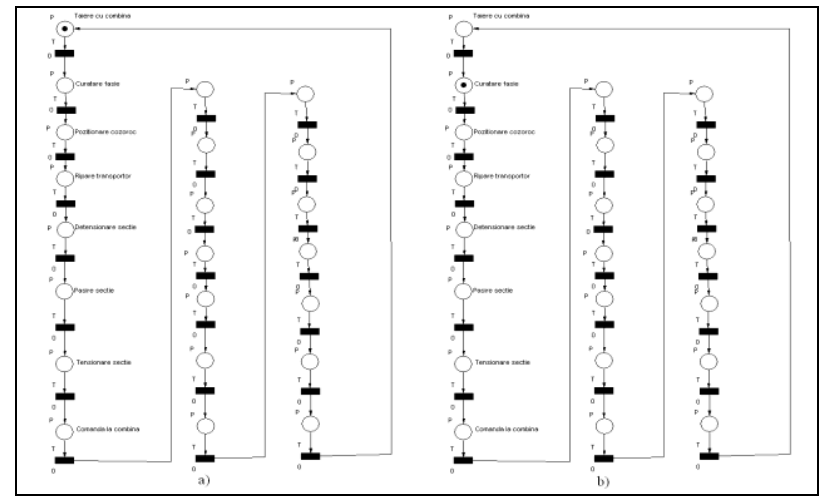

Fig. 5. Simulation with Petri Nets: a) combine cutting step; b) cleaning strip step

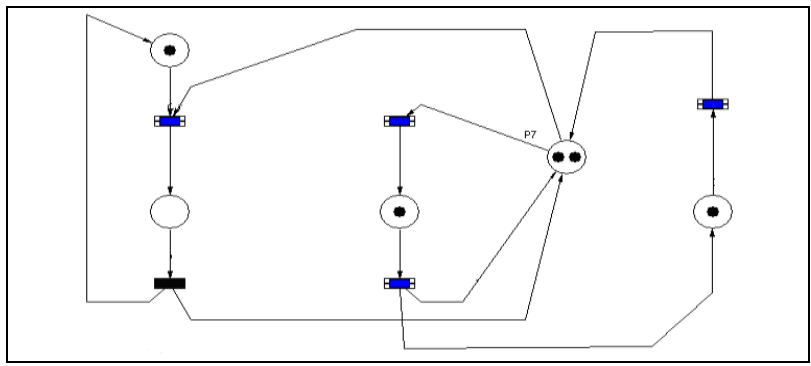

Fig. 6. Simulation with Petri Nets

\section{CONCLUSION}

For the simulation of the sustentation section it has been used the simulation environment VISUAL OBJECT $\mathrm{NET}^{++}$2.0A, that is an innovative CAD/CAE instrument for PC's useful in simulation with Petri networks that support Petri mixt, continuous and discrete events. During this software development, a great deal of attention was given to intuitive use, because of the ease in designing, quick simulation and clear documentation of Petri networks. In the current version, Petri networks events/conditions planed with infinite capacity are accepted. The paper present the functioning principles of a mechanized complex, the structure and mechanized sustentation working part of the mechanized complex, the sustentation command section modeling realization and the mechanized complex with Petri networks and, also, present the sustentation command section simulation realization and the mechanized complex with Petri networks using Visual Object Net simulation environment.

\section{REFERENCES}

[1] Egri, A, ; Sirb, V. ; (2010). Hibrid control system for flexibile fabrication systems. XXIV.microCAD 2010, International Scientific Conference.ISBN 976-963-661-925-1 O, ISBN 976963-661-909-5

[2] Patrascoiu, N, ; (2001). Modeling and simulation system. Expert systems in the manufactures, Publishing Focus, Petrosani, ISBN 973-8035-34-1

[3] Sirb, V. ; Egri, A, ; (2010). Modeling, simulation and control of flexibile manufacturing system. Annals of DAAAM for 2010 \& ISI Proceedings, ISSN 1726-9687, ISBN 978-3-901509-83-4

[4] Sirb, V. ; (2008). Contributions Concerning the Modelling, Simulation and Prototyping of CIM Type Systems. - PhD thesis, Petrosani 